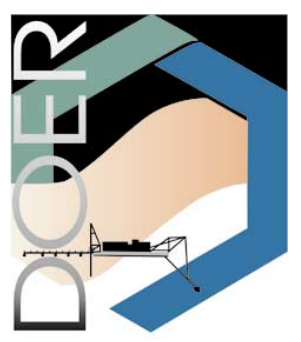

\title{
Erosion Rates and Bulk Properties of Dredged Sediments from Mobile, Alabama
}

PURPOSE: This technical note (TN) details analysis of bulk properties and erosion rates for dredged material from the Mobile River placed offshore of Mobile Bay, AL. The specific goal of this research is to develop methods of associating sediment erosion rates to material bulk properties.

BACKGROUND: It is well documented (Jepsen, McNeil, and Lick 2000; Roberts et al. 1998; Jepsen, Roberts, and Lick 1997) that sediments that consist of sand, silt, and clay mixtures (mixed sediments) have significantly more complex erosion characteristics than pure sand or predominately sandy sediments. These mixed sediments are often referred to as cohesive because of the tendency of the particles to adhere to each other. The erosion characteristics of these sediments cannot be described using the well-established methods used for sandy sediments, where erosion is primarily a function of grain size and size distribution. Mixed sediment erosion rates are affected not only by grain size, but also by bulk density, mineralogy, pore water chemistry, organic content, the presence of gas bubbles, and other factors. It is qualitatively understood that, depending on the conditions, one or more of these bulk properties may have an order of magnitude or more effect on erosion rates. However, insufficient data are available to quantify the effects of these parameters. At present, when attempting to quantify erosion or dispersion characteristics of a mixed sediment bed, site-specific sediment erosion tests are required at significant cost and time commitment. In addition, because bulk density affects erosion rates, these rates will change with depth below the sedimentwater interface, adding an additional level of complexity to the site-specific experiments.

The majority of sediments dredged by the U.S. Army Corps of Engineers (USACE) are classified as mixed (cohesive) sediments. This complicates selection of Open-Water Dredged Material Disposal Sites (ODMDS). Federal and state regulatory agencies frequently require a quantitative understanding of a site's dispersion (erosion and subsequent transport) characteristics before approving the site. This has delayed dredging operations in the past because the site-specific erosion characteristics must be quantified through laboratory and field experiments before the Environmental Impact Statement (EIS) could be developed.

A quantitative understanding of how sediment properties affect erosion rates would permit reasonable quantitative estimates of site dispersion without the presently required cost and time commitments of laboratory or field experiments. Therefore, under the Dredging Operations and Environmental Research (DOER) program, the Corps has undertaken efforts to contribute to the existing database of sediment properties and erosion potentials. This will lead to a classification system for sediments that will assist in developing predictive models for the site of interest. From this database, the DOER program will develop a method for classification of a site as highly, moderately, or minimally dispersive under known forcings (currents and waves) if the bulk properties of the sediments of interest are known. The effort to develop this database includes erosion and sediment property analysis of field samples and well-controlled laboratory samples. 
This TN documents analysis for one of the field sites selected under the DOER program. The site is an ODMDS created offshore approximately 8 miles south of the entrance to Mobile Bay and Dauphin Island, AL (Figure 1, mixed sediment mound). Dredged material placement at the site began in late October 1998. A total of 350,000 cu yd of cohesive (mixed) dredged material was placed in the mound. The material was dredged from the Mobile River in the upper reaches of Mobile Bay. The placement area was located on the southwestern edge of the entrance ebb shoal

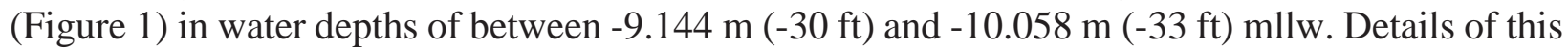
study are provided in Davis, Stauble, and Rollings (2000). Postplacement multibeam surveys indicated the dredged material mound had an irregular footprint and the highest peaks in the mound

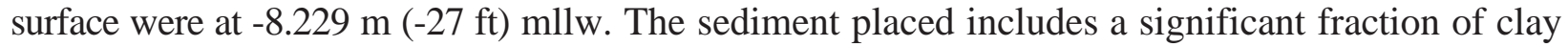
and silt particles and behaves in a cohesive manner. Visual inspection of the material indicated that it appeared to be mud with a high water content and some sand evident. This document includes information on the sediment bulk properties, erosion rates, and variation of erosion rates with depth below the sediment-water interface (bulk density).
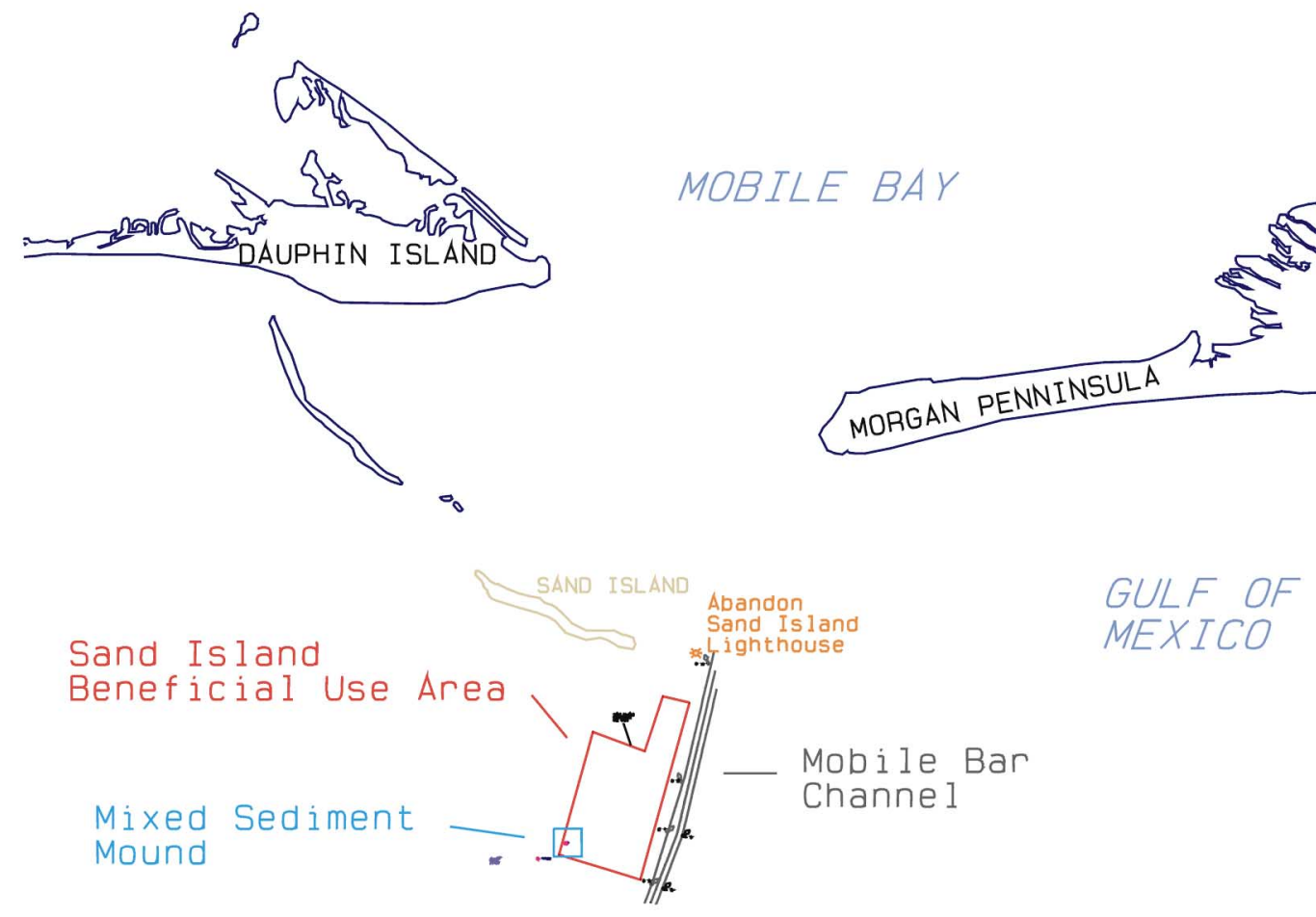

Figure 1. Location of mixed sediment dredged material mound placed offshore of Mobile Bay

The remainder of this TN is divided into four sections. The first section describes previous research on cohesive sediment erosion potential as a function of the sediment bulk properties. The second section describes the experimental procedures with particular emphasis on the unique high-shear flume (Sedflume) required to obtain the erosion data. The third section describes the results of the Mobile sediment analysis and, finally, the fourth section includes concluding remarks. 
PREVIOUS RESEARCH: It is well documented that at moderate shear stresses $(<1.5 \mathrm{~Pa})$ cohesive sediment erosion can be estimated as a function of the applied shear stress in the form of the equation

$$
\begin{array}{ll}
\varepsilon=A\left(\frac{\tau-\tau_{c r}}{\tau_{c r}}\right)^{n} & \tau>\tau_{c r} \\
\varepsilon=0 & \tau \leq \tau_{c r}
\end{array}
$$

where $\varepsilon$ is the total amount of resuspension possible under a given shear stress $\left(\mathrm{g} / \mathrm{cm}^{2}\right), \tau$ is the applied shear stress, $\tau_{c r}$ is the critical shear stress below which no erosion occurs, and $A$ and $n$ are site-specific variables (Partheniades 1965; Krone 1962; Fukuda and Lick 1980). $A$ and $n$ are site-specific and a function of the previously stated bulk properties of the sediment and can vary significantly. Review of the literature indicates that $A$ can vary by orders of magnitude and $n$ can range from 1 to 5 (Lavelle, Mofield, and Baker 1984). Therefore, application of this equation to estimate erosion rates is difficult unless the site-specific erosion tests are performed to estimate the site-specific variables. In addition, Equation 1 as originally developed implies that there is a finite amount that can be suspended under a given shear stress due to effects of armoring. This is true for moderate shear stresses, but under high shear stress (storm conditions), most sediments continue to erode until a bulk property such as bulk density changes the value of $\tau_{c r}$. The flume used in the present experiments (Sedflume) was designed to address the situation of high shear stress and variation of sediment properties, critical shear stress, and erosion rate with depth below the sediment-water interface.

In addition, more recent research indicates that Equation 1, which works well at high shear stress for noncohesive sediment, fails at these high stresses to accurately reflect cohesive sediment processes. This will be discussed later. Therefore, many of the cohesive sediment erosion algorithms developed under low-shear conditions may not be applicable at the higher shear stresses found at ODMDS during storms.

Related investigations prior to this study that used Sedflume include analysis of erosion rates and bulk properties of undisturbed sediments from the Detroit River in Michigan, the lower Fox River in Wisconsin, the Grasse River in New York, Lake Michigan, Long Beach Harbor in California, and a dredged material placement site offshore of New York Harbor (McNeil, Taylor, and Lick 1996; Taylor and Lick 1996; Jepsen, Roberts, and Lick 1997; McNeil, Jin, and Lick 2000). These tests have illustrated the large differences in erosion rates (by as much as several orders of magnitude) at different sites, with depth in the sediments, and as a function of shear stress. In addition, these tests qualitatively determined that erosion rates depend on at least the following parameters: bulk density, particle size (mean and distribution), mineralogy, organic content, salinity of the pore water, amount of gas, oxidation or other chemical reactions, and consolidation time. For the purposes of understanding and accurately predicting erosion rates, the dependence of erosion rates on these parameters needs to be known.

Sedflume, used in the experiments previously described, is a unique flume that can measure the erosion rates of sediments at high shear stresses comparable to those found in the nearshore during storms (up to stresses on the order of $20 \mathrm{~N} / \mathrm{m}^{2}$ ). Sedflume also has the capability to measure the 
variation in erosion rates with depth below the sediment-water interface (down to a meter or more). Although Sedflume was designed and has been used to measure the erosion rates of undisturbed natural sediments from a field site, it can also be used to measure erosion rates of sediments that have been reconstructed in the laboratory so as to obtain sediments with well-defined properties.

As an example of this, Sedflume has been used with reconstructed sediments to quantitatively determine the effects of bulk density on erosion rates (Jepsen, Roberts, and Lick 1997). The sediments used were from the Detroit River, the lower Fox River, and the Santa Barbara Slough. For each of these sediments and for consolidation times varying from 1 to 60 days, the erosion rate as a function of shear stress and depth was measured and related to the local bulk density of the sediment. From these experiments, it was determined that, for each type of sediment, the erosion rate was a unique function of the bulk density and shear stress and could be approximated by:

$$
\begin{array}{ll}
E=A \tau^{n} \rho^{m} & \tau>\tau_{c r} \\
E=0 & \tau \leq \tau_{c r}
\end{array}
$$

where $E$ is the erosion rate $(\mathrm{cm} / \mathrm{sec}) ; \tau$ is the shear stress $\left(\mathrm{N} / \mathrm{m}^{2}\right) ; \rho$ is the bulk density $\left(\mathrm{g} / \mathrm{cm}^{3}\right)$; and $A, n$, and $m$ are constants that depend on the type of sediment and include the affects of the bulk properties (other than bulk density) previously listed. Equation 2 is similar to Equation 1, except it does not include the critical shear stress term. Equation 2 is designed for high shear stress, where $\tau_{\mathrm{cr}}<<\tau$. Under these conditions, critical shear stress becomes less important in the equation. In addition, accounting for the critical shear stress term and incorporating the $\rho^{m}$ term into the $A$ term, Equation 2 is equivalent to Equation 1. The form of the erosion equation presented in Equation 2 is similar to that presented by Ariathurai and Krone (1962), except that equation presumed $n=1$.

In a related set of experiments, the effects of particle size and bulk density on the erosion of quartz particles were investigated (Roberts et al. 1998). Average particle sizes ranged from 5 to $1350 \mu \mathrm{m}$, while bulk densities ranged from approximately 1.65 to 1.95 . For the larger particles (>60 $\mu \mathrm{m})$, the sediments behaved in a noncohesive manner, i.e., they consolidated rapidly and the surface eroded particle by particle. For the smaller particles $(<60 \mu \mathrm{m})$, the sediments behaved in a cohesive manner, i.e., they consolidated slowly and the surface eroded in particles and chunks. The data were well approximated by Equation 2 except for the larger, noncohesive particles (d > $220 \mu \mathrm{m})$. For these particles, the data were better approximated by Equation 1. There was a strong inverse relationship to bulk density for the finer particles and the rates were independent of density for the larger particles.

Several authors have investigated gas generation in sediments and its effect on the flux of contaminants by gas ebullition (expulsion), e.g., see Adams, Fendinger, and Glotfelty (1990). In fine-grained sediments, gas loss from the sediments was typically shown to be on the order of $1 \mathrm{~L} / \mathrm{m}^{2} /$ day. This movement of gas also significantly affected the flux of organic chemicals from the sediments.

Gas generation effects on the density and erosion rates of sediments have been investigated by Jepsen, McNeil, and Lick (2000) and McNeil, Jin, and Lick (2000) and were found to be significant in both investigations. The gas generation was due to the decay of organic matter. In general, the gas volume in the sediments increased with time but eventually seemed to reach a reasonably steady 
state. Bulk densities and erosion rates varied with time due to compaction of the solid-water matrix (upward movement of water) and gas generation and upward movement; these densities and erosion rates also eventually reached a reasonably steady state due to a balance between these factors.

An investigation of the effect of adding bentonite (a clay composed primarily of montmorillonite, a member of the smectite family) to sediments has also been made (Jin, McNeil, and Lick 2000). In this study, small amounts of bentonite were added to three types of sediment (a topsoil, a sand, and a 50/50 mix of the two). Erosion rates decreased rapidly as the amount of bentonite increased. For example, the addition of 2 percent bentonite to any of these sediments caused a decrease in erosion rates by one to two orders of magnitude at each shear stress investigated $\left(0.2\right.$ to $\left.12.8 \mathrm{~N} / \mathrm{m}^{2}\right)$. The addition of larger amounts of bentonite caused further decreases in erosion rates, but the decreases were of lesser magnitude as the amount of bentonite increased.

EXPERIMENTAL PROCEDURES: The information in this section is based on the articles by McNeil, Taylor, and Lick (1996); Taylor and Lick (1996); and Jepsen et al. (1997). The user is referred to these articles for further details.

Sedflume Description. Sedflume (Figures $2 \mathrm{a}$ and $2 \mathrm{~b}$ ) is essentially a straight flume that has a test section with an open bottom through which a rectangular cross-section coring tube containing sediment can be inserted. The main components of the flume are: the coring tube; the test section; an inlet section for uniform, fully developed, turbulent flow; a flow exit section; a water storage tank; and a pump to force water through the system. The coring tube, test section, inlet section, and exit section are made of clear acrylic so that the sediment-water interactions can be observed. The coring tube has a rectangular cross section, $10 \mathrm{~cm}$ by $15 \mathrm{~cm}$, and can be up to $1 \mathrm{~m}$ in length.

Water is pumped through the system from a 500-L storage tank, through a 5-cm diameter pipe, and then through a flow converter into the rectangular duct. The flow converter changes the shape of the cross section from circular to the rectangular duct shape while the cross-sectional area remains constant. The rectangular duct is $2 \mathrm{~cm}$ in height, $10 \mathrm{~cm}$ in width, and $120 \mathrm{~cm}$ in length; it connects to the test section, which has the same cross-sectional area and is $15 \mathrm{~cm}$ long. A three-way valve regulates the flow so that part of the flow goes into the duct while the remainder returns to the tank. There is a small valve in the duct immediately downstream from the test section that is opened at higher flow rates to keep the pressure in the duct and over the test section at atmospheric conditions.

In general, at the start of each test, the coring tube has been filled with either reconstructed or undisturbed sediments from the bottom of the water body of interest. However, in the present investigation, only reconstructed sediments were used. The procedure for preparing these reconstructed sediments is described in the following paragraphs. The coring tube and the sediment it contains are inserted into the bottom of the test section. An operator moves the sediment upward using a piston inside the coring tube and is connected to a hydraulic jack with a 1-m drive. The jack is driven by the release of pressure regulated with a switch and valve system. By this means, the sediments can be raised and made level with the bottom of the test section. The movement of the jack can be controlled in measurable increments as small as $0.5 \mathrm{~mm}$. Water is forced through the duct and the test section over the surface of the sediments. The shear stress produced by this flow causes the sediments to erode. As the sediments in the core erode, they are continually moved 
ERDC TN-DOER-N10

April 2001
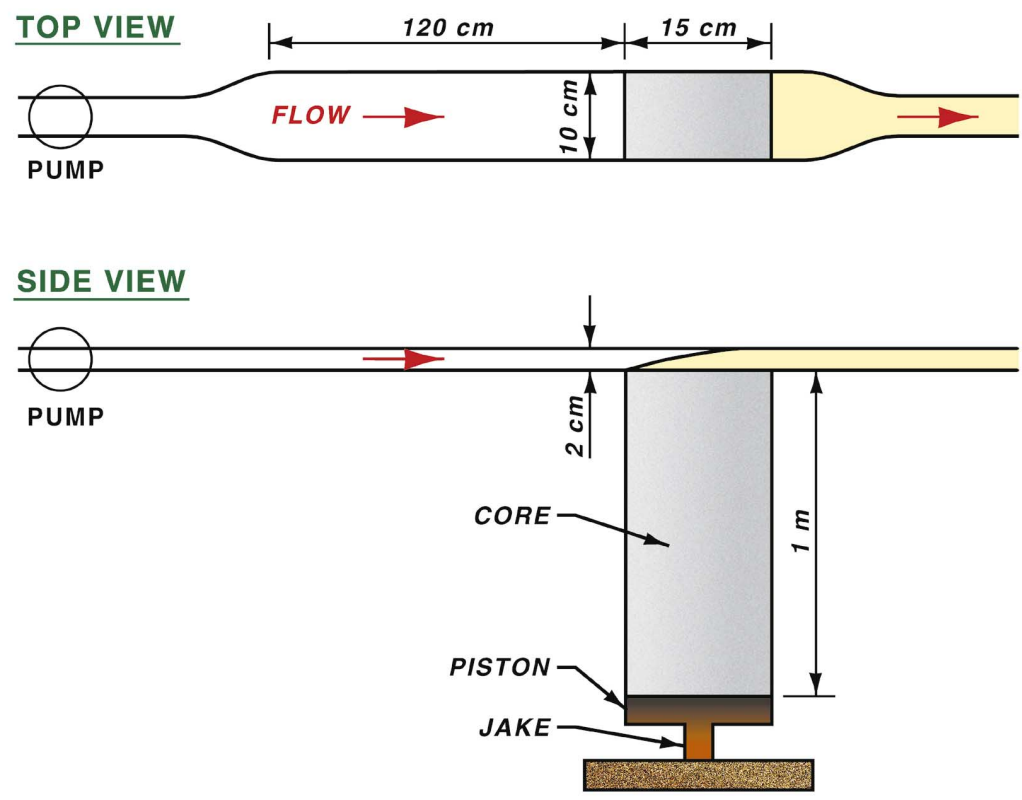

a. Schematic of Sedflume

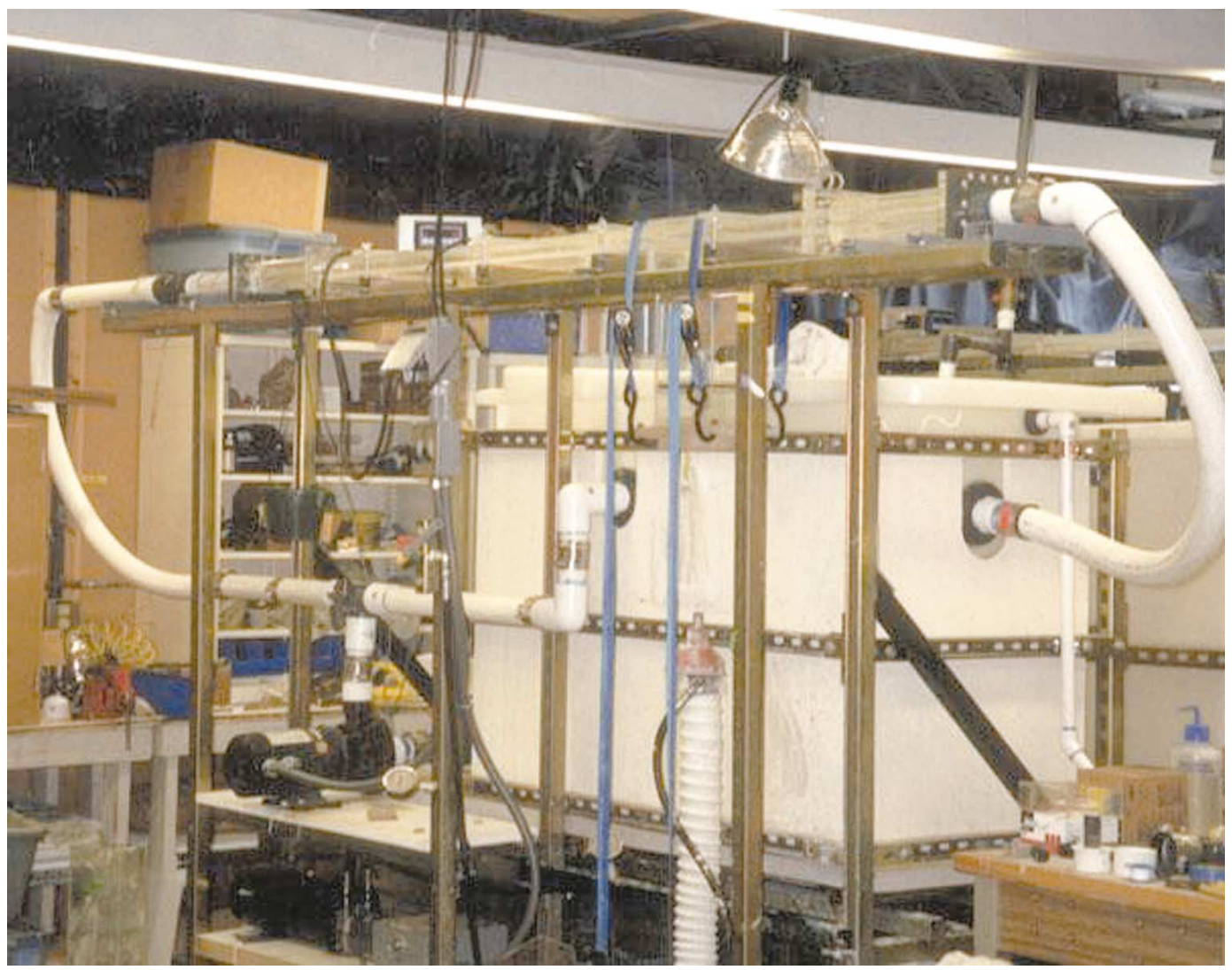

b. University of California, Santa Barbara (UCSB), flume

Figure 2. Sedflume 
upwards by the operator so that the sediment-water interface remains level with the bottom of the test and inlet sections. The erosion depth at a particular shear stress (flow rate) is recorded as the upward movement of the sediments in the coring tube over a specified time interval.

Core Collection and Preparation. Sedflume tests were done with well mixed, reconstructed sediments obtained from the ODMDS offshore of Dauphin Island (Figure 1). To obtain different bulk densities for the sediments for the erosion tests, sediment cores were prepared as follows. Approximately 20 gal of wet sediments were placed in a 30-gal cylindrical tank and mixed until the sediment-water mixture was homogeneous and without gas. The sediment mixture was then poured into 20 -cm coring tubes. To prevent stratification and ensure an initial homogeneous sediment/water mixture, the cores were allowed to consolidate for two days after which the overlying water was removed from the top of the cores. The cores were then each remixed. This was done twice for each core. The cores were then allowed to consolidate for durations ranging 1 to 182 days. During this time, the bulk density was monitored as a function of depth and time by means of the density profiler (Gotthard 1998). Operation of the density profiler will be discussed later.

Erosion Rate Measurements. The procedure for measuring the sediment erosion amount at a specified shear stress and depth below the sediment-water interface was described in the previous section. Erosion rates are estimated by dividing erosion amount by the time interval. The following procedure was used to measure erosion rates at multiple shear stresses using an individual core. Starting at a low shear stress, the flume was run sequentially at higher shear stresses with each succeeding shear stress being twice the previous one. Generally, about three to five shear stresses were run sequentially. Each shear stress was run until at least 0.5 to $1.0 \mathrm{~mm}$, but no more than $2 \mathrm{~cm}$, was eroded. If no erosion was detected after $10 \mathrm{~min}$, erosion rate was recorded as zero. The time interval was recorded for each run with a stopwatch. The flow was then increased to the next shear stress, and so on until the highest shear stress was run. This cycle was repeated until all of the sediment had eroded from the core. If after three cycles a particular shear stress showed a rate of erosion less than $2 \times 10^{-5} \mathrm{~cm} / \mathrm{sec}$, it was dropped from the cycle; if after many cycles the erosion rates decreased significantly, a higher shear stress was included in the cycle.

Measurements of Critical Shear Stress for Erosion. A critical shear stress can be quantitatively defined as the shear stress at which a very small, but accurately measurable, rate of erosion occurs. In the present study, this rate of erosion was chosen to be $1 \times 10^{-4} \mathrm{~cm} / \mathrm{sec}$, representing approximately $1 \mathrm{~mm}$ of erosion in $15 \mathrm{~min}$. Since it would be difficult to measure all critical shear stresses at exactly $1 \times 10^{-4} \mathrm{~cm} / \mathrm{sec}$, erosion rates were generally measured above and below $1 \times 10^{-4} \mathrm{~cm} / \mathrm{sec}$ at shear stresses that differ by a factor of two. The critical shear stress was then linearly interpolated to an erosion rate of $1 \times 10^{-4} \mathrm{~cm} / \mathrm{sec}$. This method provides results with approximately 20 percent accuracy for the critical shear stress. Alternatively, the value of $\tau_{c}$ can be determined directly from Equation 1, which, after rearranging becomes

$$
\tau_{c}=\left(\frac{E}{A}\right)^{1 / n} \rho^{-m / n}
$$

where $\mathrm{E}=1 \times 10^{-4} \mathrm{~cm} / \mathrm{sec}$ and the constants $A, n$, and $m$ are determined from the erosion experiments. 
Bulk Properties Measurements. To assess the parameters that affect sediment erosion, bulk properties including bulk density, water content, median particle size, organic content, and sediment gas volume were determined as a function of depth. Sediment bulk densities were measured nondestructively as a function of depth by means of the density profiler (Gotthard 1998). The density profiler gives a detailed, nondestructive measurement of bulk density. Only a few grams of sediment are needed for measuring the other bulk parameters, so small amounts of sediment were removed during the erosion tests at various depths within the core for these measurements. This procedure eliminates the use of duplicate cores, one for bulk properties and one for erosion tests.

The density profiler uses a gamma radiation emitter, ${ }^{137} \mathrm{Cs}$, as a radiation source and measures the attenuation of the radiation as it is transmitted horizontally through the sediments. Once the transmitted radiation is measured, this can be directly related to density of the sediments in the core (Gotthard 1998).

The density profiler measures the actual sediment density, including solids, water, and any gas present. In contrast, the standard procedure for measuring sediment density measures the sediment density due to solids and water, and ignores the presence of gas. As shown in the following paragraphs, by measuring both densities, the gas volume in the sediments can be determined.

The standard procedure for determining density as used here is as follows. Sediment cores are sliced into 1- to $2-\mathrm{cm}$ sections and weighed (wet weight, $m_{w}$ ). They are then dried in the oven at approximately $75^{\circ} \mathrm{C}$ for 2 days and weighed again (dry weight, $m_{d}$ ). In terms of $m_{w}$ and $m_{d}$, the moisture content, $W$, is given by:

$$
W=\frac{m_{w}-m_{d}}{m_{w}}
$$

This procedure generally eliminates any gas originally present in the sediments. The bulk density as determined by this method, $\rho^{*}\left(\mathrm{~g} / \mathrm{cm}^{3}\right)$, is related to the moisture content by:

$$
\rho *=\frac{\rho_{s} \rho_{w}}{\rho_{w}+\left(\rho_{s}-\rho_{w}\right) W}
$$

where $\rho_{s}=2.6 \mathrm{~g} / \mathrm{cm}^{3}$ and is the density of the solid particles, and $\rho_{w}=1.0 \mathrm{~g} / \mathrm{cm}^{3}$ and is the density of the water.

From their definitions, $\rho^{*}=m_{s w} / V_{s w}$ and $\rho=m_{s w} /\left(V_{s w}+V_{g}\right)$, where $m_{s w}$ is the mass of the solids and water, $V_{s w}$ is the volume of the solids and water, and $V_{g}$ is the volume of the gas within the sediments. The total volume, $V$, is given by $V_{s w}+V_{g}$. From these definitions, the fractional gas volume, $v_{g}=V_{g} / V$, can be shown to be:

$$
v_{g}=\frac{\rho^{*}-\rho}{\rho^{*}}
$$


Particle sizes and particle size distributions were determined by use of a Malvern particle sizer for particle diameters between 0.5 and $600 \mu \mathrm{m}$. All sediment samples had particle sizes less than $600 \mu \mathrm{m}$. A small amount of sediment was mixed with water and disaggregated in a Waring blender. Approximately $1 \mathrm{~mL}$ of this solution was then used for analysis by the particle sizer. From these measurements, the median and the distribution of grain sizes as a function of depth were obtained.

The organic carbon content was determined by extracting approximately $5 \mathrm{~mL}$ of the sediment water mixture that was disaggregated in the Waring blender as previously described and then drying it in an oven at $75^{\circ} \mathrm{C}$. The dry sediment was crushed into powder and weighed. Approximately $5 \mathrm{~mL}$ of 10 percent hydrochloric acid was added to every $1 \mathrm{~g}$ of dry sediment. The sample was again dried in the oven at $75{ }^{\circ} \mathrm{C}$ and analyzed in a Leeman Labs Model $440 \mathrm{CHN}$ Analyzer at the UCSB Marine Science Analytic Laboratory to determine the total organic carbon content of the sediment.

The mineralogy of the sediments was approximately determined by means of X-ray powder diffraction by Reed Glasmann (Willamette Geological Service, Philomath, OR). The measurements for the field sediments were taken at depths of 5 to $10 \mathrm{~cm}$. The clay-size $(<2 \mu \mathrm{m})$ and silt-size $(2-15 \mu \mathrm{m})$ fractions of the sediments had high concentrations of clay minerals. In the clay-size fraction, the minerals were primarily smectite (the most cohesive of the clays), illite, and kaolinite. Of the total sediment mass, it is estimated that the smectite mass was about 8 percent, a concentration much higher than those in the Fox $(1.5$ percent $)$ and Grasse $(<0.1$ percent $)$, rivers that were previously investigated.

Measurements were also made of the water soluble and exchangeable fractions of manganese $\left(\mathrm{Mn}^{2+}\right)$ and iron $\left(\mathrm{Fe}^{2+}\right.$ and $\left.\mathrm{Fe}^{3+}\right)$ by means of extraction with ammonium acetate. The effects on erosion of the oxidation processes that produces these exchangeable fractions will be demonstrated later in this report. The chemical analysis was performed by the Marine Science Analytical Laboratory at UCSB. $\mathrm{Mn}^{2+}$ concentrations were determined to be approximately $84 \mu \mathrm{g} \mathrm{Mn}^{2+} / \mathrm{g}$ dry sediment, a concentration much higher than those in the bottom sediments of the Fox $(22 \mu \mathrm{g} / \mathrm{g})$, Detroit $(2 \mu \mathrm{g} / \mathrm{g})$, and Grasse $(22 \mu \mathrm{g} / \mathrm{g})$ rivers. Exchangeable manganese concentrations were also much greater than exchangeable iron concentrations for all of these sediments, but especially for the Mobile sediments.

\section{RESULTS}

General Characteristics of Sediments. Bulk properties and erosion rates were measured for well-mixed (or reconstructed) sediments collected from five locations on the mixed sediment mound (Figure 1). A summary of this data is shown in Table 1 which lists the median particle size $\left(\mathrm{D}_{50}\right)$, organic content, gas fraction (for long time), bulk density after 60 days of consolidation, the critical shear stress for erosion, and the coefficients $A, n$, and $m$ for Equation 1 for all sites. The averages of these quantities over all five locations are also listed.

The median particle sizes were about $21 \mu \mathrm{m}$ with little deviation between sites. Organic contents were (1.0 percent) compared to other sites previously investigated. As a result of the low organic contents, gas fractions were also low (1.0 percent). Densities for all sediments were similar; they increased with time, but at 60 days they were about $1.49 \mathrm{~g} / \mathrm{cm}^{3}$. The critical shear stresses for erosion were very high, approximately $1.5 \mathrm{~N} / \mathrm{m}^{2}$, and significantly higher than $\tau_{c}$ for other sediments 
previously investigated, which generally varied from 0.1 to $0.4 \mathrm{~N} / \mathrm{m}^{2}$. The major reason for these high values is the oxidation reaction at the sediment-water interface and will be discussed further.

\begin{tabular}{|c|c|c|c|c|c|c|c|c||}
\hline \multicolumn{2}{|c|}{ Table 1. Bulk Parameters and Surface Critical Shear Stresses for All Sites } \\
\hline \hline & $\begin{array}{c}\mathbf{D}_{\mathbf{5 0}} \\
(\mu \mathbf{m})\end{array}$ & $\begin{array}{c}\text { Organic } \\
\text { Content } \\
\text { (percent) }\end{array}$ & $\begin{array}{c}\text { Gas } \\
\text { Fraction } \\
\text { (percent) }\end{array}$ & $\begin{array}{c}\text { Density } \\
\text { at } \mathbf{6 0} \text { days } \\
\left(\mathbf{g} / \mathbf{c m}^{\mathbf{3}}\right)\end{array}$ & $\begin{array}{c}\tau_{\mathbf{c}} \\
\left(\mathbf{N} / \mathbf{m}^{2}\right)\end{array}$ & $\boldsymbol{A}$ & $\boldsymbol{n}$ & $\boldsymbol{m}$ \\
\hline \hline PD1 & 21.0 & 1.12 & 1.20 & 1.48 & 1.27 & $3.5 \times 10^{17}$ & 3.46 & -132 \\
PD2 & 19.6 & 1.37 & 0.73 & 1.48 & 1.20 & - & - & - \\
PD3 & 21.7 & 1.09 & 1.10 & 1.49 & 1.84 & $2.0 \times 10^{31}$ & 2.00 & -207 \\
PD4 & 20.8 & 0.55 & 1.05 & 1.49 & 1.60 & $1.8 \times 10^{31}$ & 3.06 & -209 \\
PD5 & 22.4 & 0.87 & 1.05 & 1.52 & 1.74 & $4.3 \times 10^{16}$ & 4.16 & -126 \\
\hline \hline Average & 21.1 & 1.0 & 1.03 & 1.49 & 1.53 & - & - & - \\
\hline \hline
\end{tabular}

As indicated by the quantities in Table 1, the bulk parameters for all five locations were similar. It is not as obvious from the values of $A, n$, and $m$ in Table 1 that the erosion rates are also similar for the locations. The higher values of $A$ at locations PD3 and PD4 are negated by the lower values of $m$ for these locations. When plotted, it can be shown that erosion rates for the various locations are similar. Therefore, only sediments from one site, PD1, will be discussed in detail.

General Characteristics of Erosion. After thorough mixing, the sediments throughout the cores were initially uniform in color, texture, general appearance, and particle size. However, after a few minutes to a few hours following deposition, a thin layer of lighter-colored sediment began to form at the sediment-water interface. As time increased, the thickness of this layer increased to about 5 to $7 \mathrm{~mm}$ after 60 days of consolidation. The density of this layer was significantly lower (about $1.35 \mathrm{~g} / \mathrm{cm}^{3}$ ) than that of the darker sediment below (about $1.5 \mathrm{~g} / \mathrm{cm}^{3}$ ); the density of these darker sediments increased slightly with depth. This light-colored surficial layer was due to the high concentration of the manganese ion, $\mathrm{Mn}^{2+}$, in the reduced zone of the sediment and the precipitation of this ion in the form of manganese dioxide as the surface was exposed to oxygen that was present in the overlying water. This precipitate acted to cement the surficial layer.

The surficial layer, after oxidation, was very difficult to erode. The average critical shear stress for erosion was about $1.5 \mathrm{~N} / \mathrm{m}^{2}$ and was greater by about a factor of two than $\tau_{c}$ for the sediments below this layer and also much greater than $\tau_{c}$ for other sediments that have been analyzed with Sedflume. At or somewhat above the critical shear stress, the surficial, oxidized sediments typically would experience no erosion for a few minutes and would then fail catastrophically with up to $2 \mathrm{~cm}$ of sediment eroding almost instantaneously. This rate could not be quantified and only $\tau_{c}$ was recorded. The erosion rates for sediments below this layer were quantified and recorded and are discussed below for site PD1.

Sediments at depth would occasionally also erode in a catastrophic mode. In some cases, the reason was evident and was due to the oxidation of the surficial sediments; this required low erosion rates so that the diffusion of the oxidation reaction into the sediments was faster than the removal of sediments by erosion. In this case, an oxidized layer could form and catastrophic erosion then 
resulted. Below this oxidized layer, the erosion process was generally similar to that in other cohesive sediments that have been investigated. For small compaction times and low shear stresses, erosion primarily occurred as particles, aggregates, or small chunks of sediment less than $1 \mathrm{~mm}$ in diameter. As consolidation time and shear stresses increased, the sediments began eroding more as large chunks, ranging from about $1 \mathrm{~mm}$ up to $5 \mathrm{~mm}$ with some chunks even larger. Occasional catastrophic erosion (on the order of $1 \mathrm{~cm}$ of sediments) occurred for large times when the sediments were cohesive and the shear stresses were large.

Bulk Properties and Erosion Rates for PD1. Results for the bulk density as a function of depth are shown in Figure 3. Although more profiles were taken, for purposes of clarity, only the profiles for $3 \mathrm{hr}$ and 2, 8, 32, 64, 90, and 167 days are shown. For all times, the density is low at the surface in a thin layer a few centimeters thick and then increases with depth. As time increases, the density increases and also increases more rapidly with depth. This is due to water migrating upwards and out of the sediments because of the weight of the overlying sediment. Effects of gas on the density are minimal.

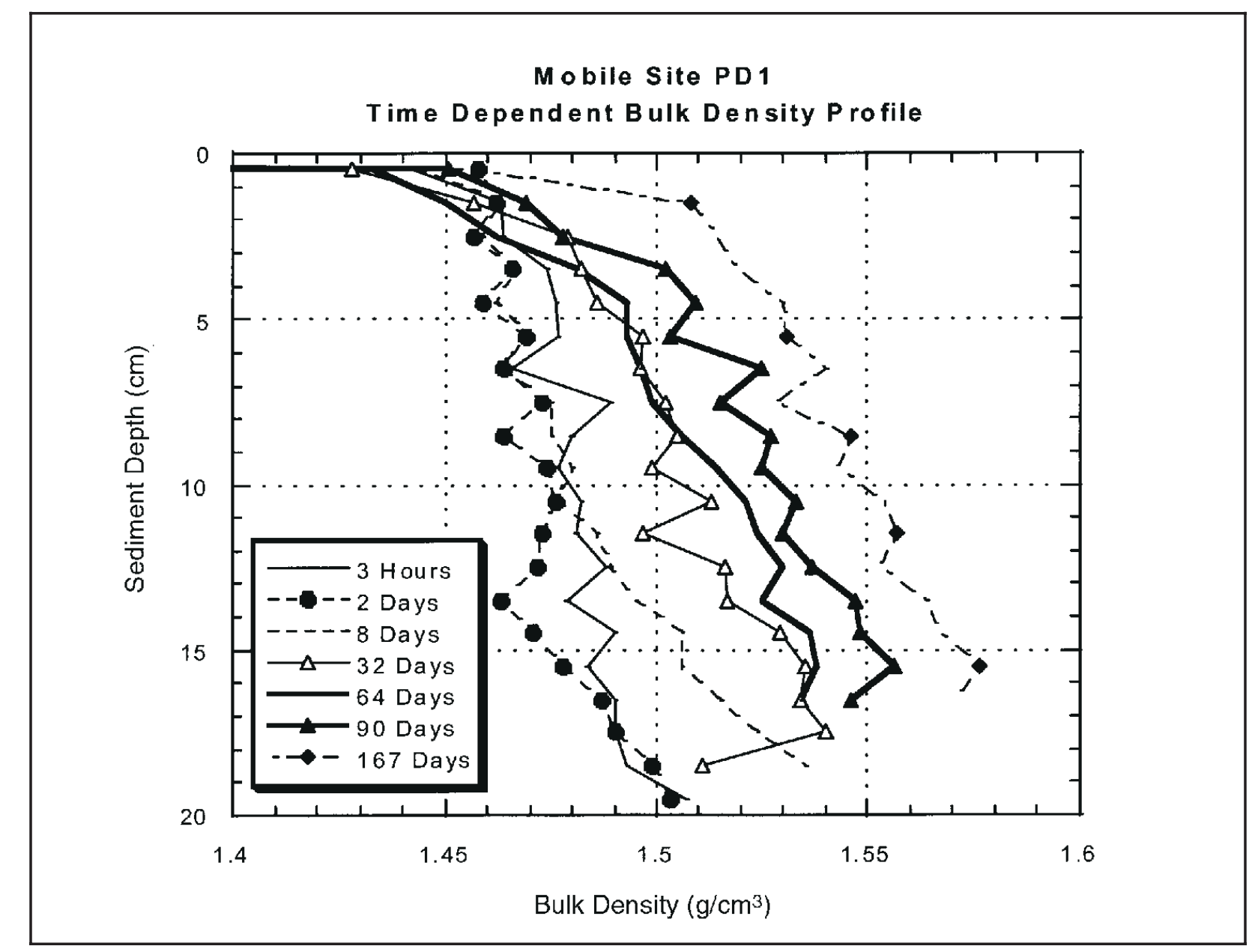

Figure 3. Bulk density as a function of depth at times after deposition of $3 \mathrm{hr}$ and 2, 8, 32, 64, 90, and 167 days 
The densities shown in the previous figure were obtained from 1-cm averages of data from the density profiler. For comparison, the densities as a function of depth at 64 days averaged over 0.1 and $1.0 \mathrm{~cm}$ are shown in Figure 4. The density averaged over only $0.1 \mathrm{~cm}$ shows large variations; this is primarily due to variations in the density of the solid-water matrix, $\rho^{*}$, since the gas fraction is less than 1 percent. The density, $\rho^{*}$ (averaged over $1 \mathrm{~cm}$ ), is also shown as a function of depth.

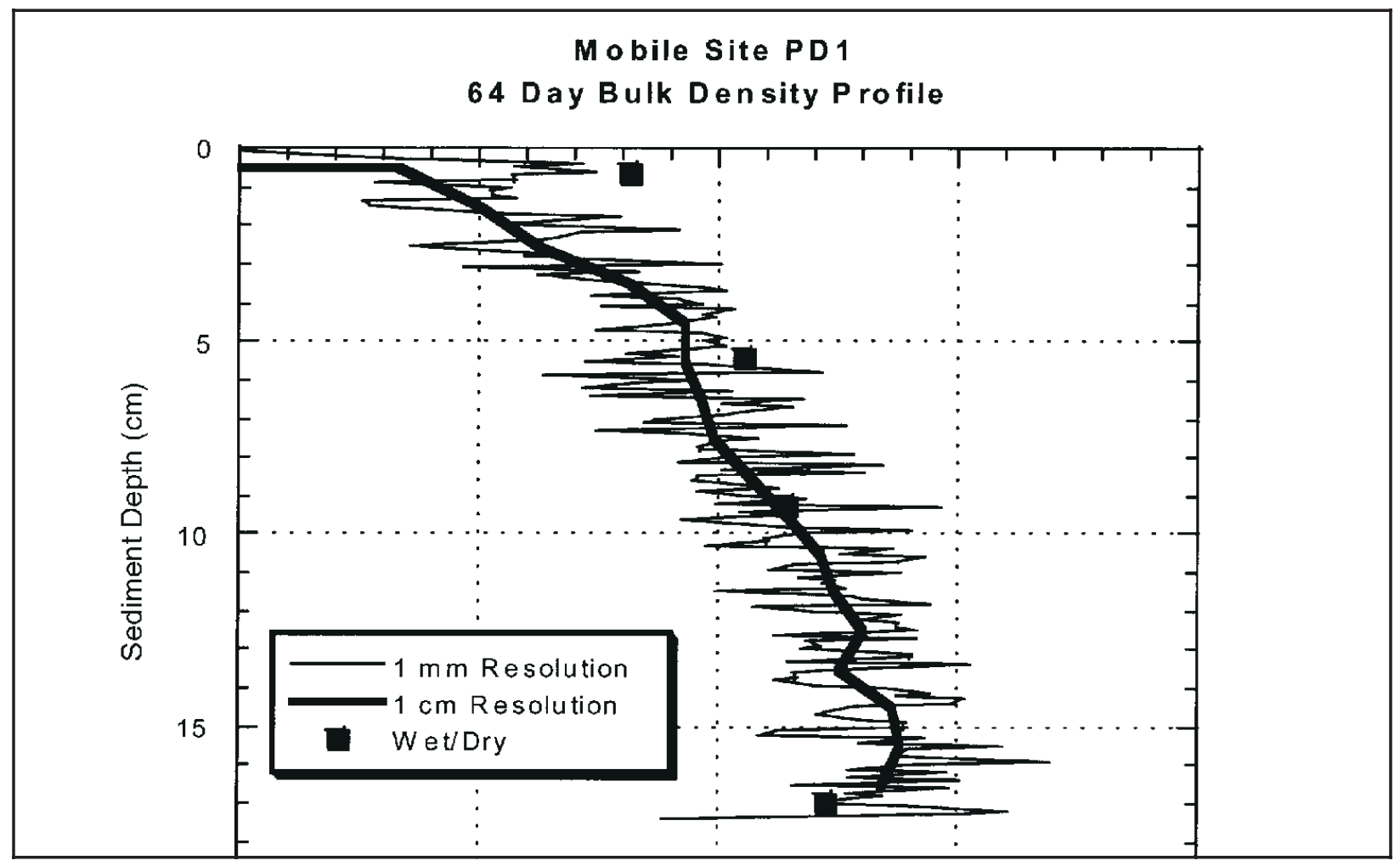

Figure 4. At 64 days, density of the solid-water matrix, $\rho^{*}$ (averaged over $1 \mathrm{~cm}$ ), as well as bulk density, $\rho$, at 0.1 and $1.0 \mathrm{~cm}$ averages as a function of depth

From $\rho$ and $\rho^{*}$, the gas fraction was determined and is shown as a function of depth at different time intervals in Figure 5. There are significant variations in the gas fraction at any particular time, but it can be seen to increase with time with reasonably steady-state average at large times between 1 and 2 percent. This is small by comparison with gas fractions in other sediments that have been investigated.

Erosion rates as a function of depth with shear stress as a parameter are shown in Figures $6 \mathrm{a}, 6 \mathrm{~b}$, $6 \mathrm{c}$, and $6 \mathrm{~d}$ for times of $1,30,60$, and 182 days of consolidation. The effects of the oxidized layer are evident in the 60- and 182-day consolidation cores. These two cores included a harder to erode surficial layer (Figures $6 \mathrm{c}$ and $6 \mathrm{~d}$ ). For all erosion tests, it can be seen that erosion rates increase rapidly with shear stress. Erosion rates also tend to decrease with depth when the oxidized surficial layer is excluded. This decrease is due to the consolidation of sediments with depth. For a particular shear stress, erosion rates decrease with time by almost three orders of magnitude over the time period of 182 days. The rate of decrease is largest for small time and decreases with time. 


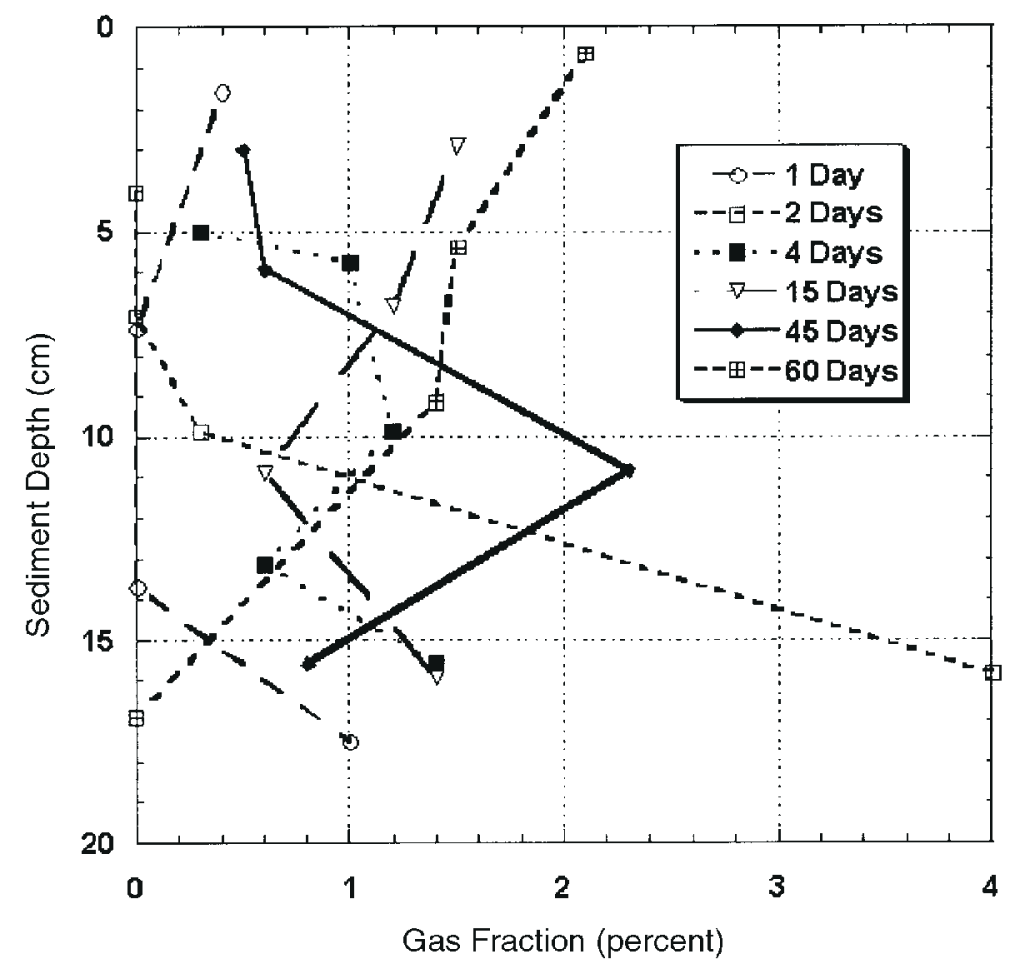

Figure 5. Gas fraction as a function of depth at times after deposition of $1,2,4,15,45$, and 60 days

Erosion rates as a function of density with shear stress as a parameter are shown in Figure 7. The data are well represented by Equation 1, i.e., (a) for each shear stress, a straight line can approximate the data, and (b) the straight lines are equidistant. For this case, $A=3.5 \times 10^{17}, n=3.46$, and $m=$ -132 in Equation 2. It should be noted that the straight lines would not be equidistant if the data were fit to Equation 1.

These rates are significantly lower than those in sediments investigated previously, by as much as an order of magnitude. The major cause of this reduction is the presence of smectite at a concentration of 8 percent. Although the effects of smectite have not been investigated directly, the effects of smectite should be quantitatively similar to those of bentonite. This amount of bentonite has been shown by Jin et al. (2000) to be sufficient to decrease erosion rates by about two orders of magnitude compared with erosion rates of the same sediment without bentonite.

CONCLUSIONS: Bulk properties and erosion rates were measured and were found to be similar for all five sites at Mobile. These sediments had high concentrations of manganese and smectite. Both of these components caused significant increases in the critical shear stress and decreases in the erosion rates of the sediments compared to other sediments that have been investigated. In particular, the high concentrations of $\mathrm{Mn}^{2+}$ precipitated as $\mathrm{MnO}_{2}$ to form a surficial layer which was very difficult to erode $\left(\tau_{c}=1.5 \mathrm{~N} / \mathrm{m}^{2}\right)$. Even after this oxidized layer was eroded, the bentonite present acted to significantly reduce the erosion rates of the sediments that were below and were not oxidized. 


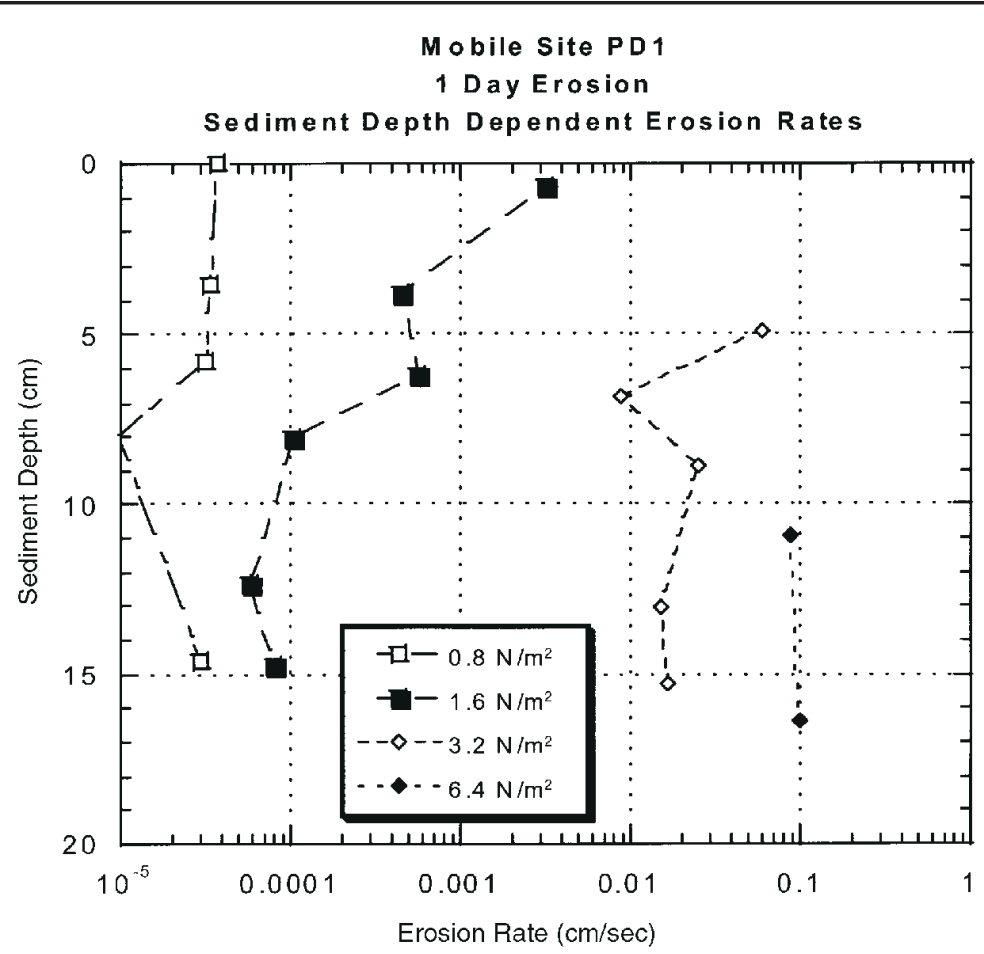

a. 1 day

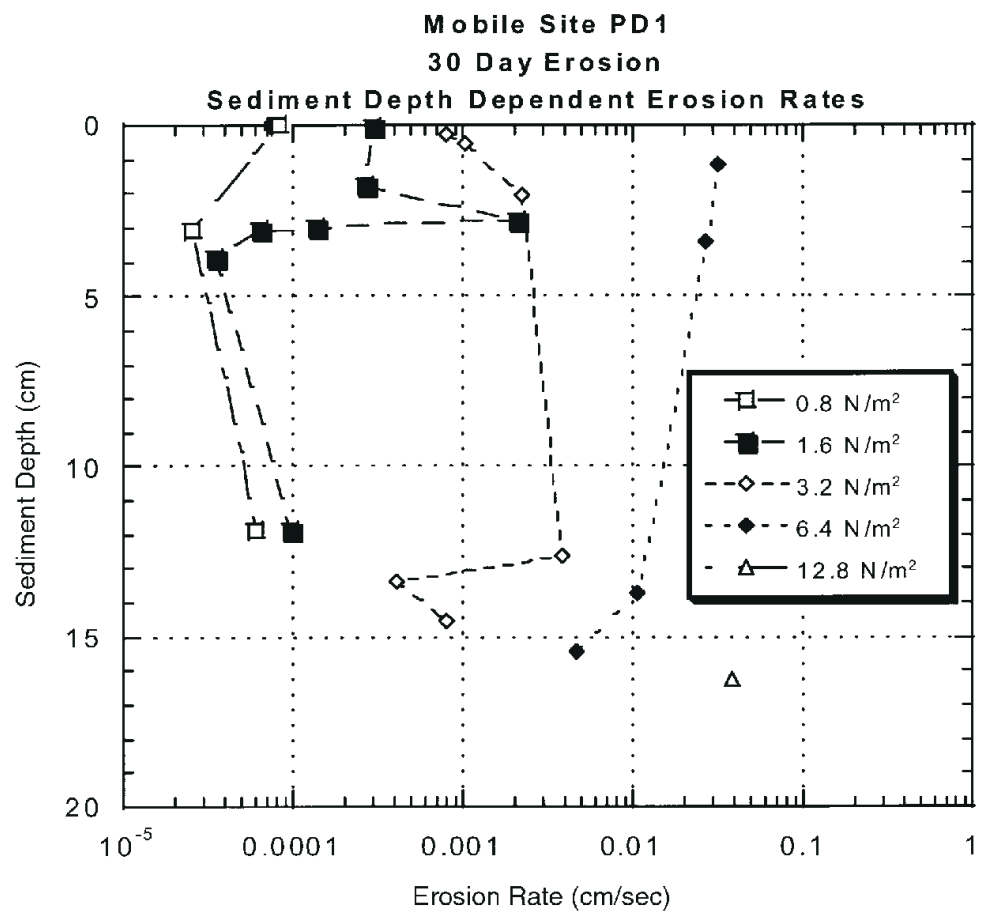

b. 30 days

Figure 6. Erosion rates as a function of depth with shear stress $\left(\mathrm{N} / \mathrm{m}^{2}\right)$ as a parameter at times after deposition (Continued) 


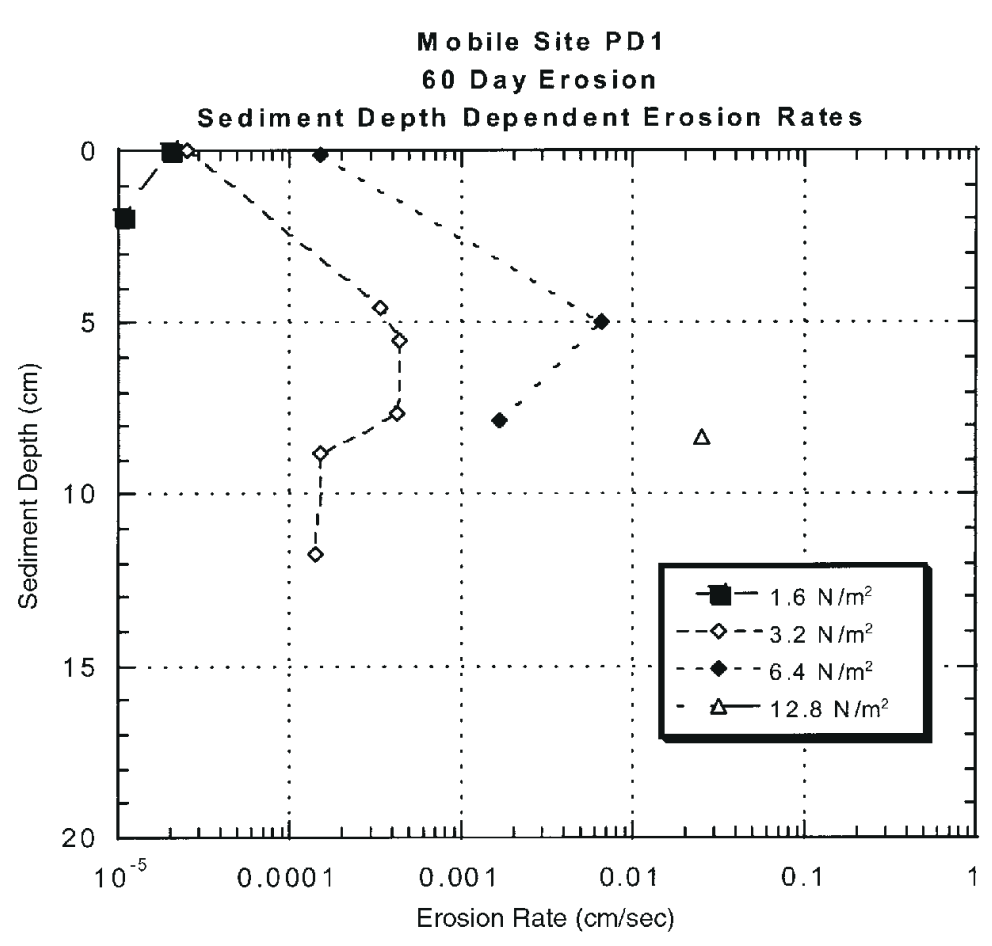

c. 60 days

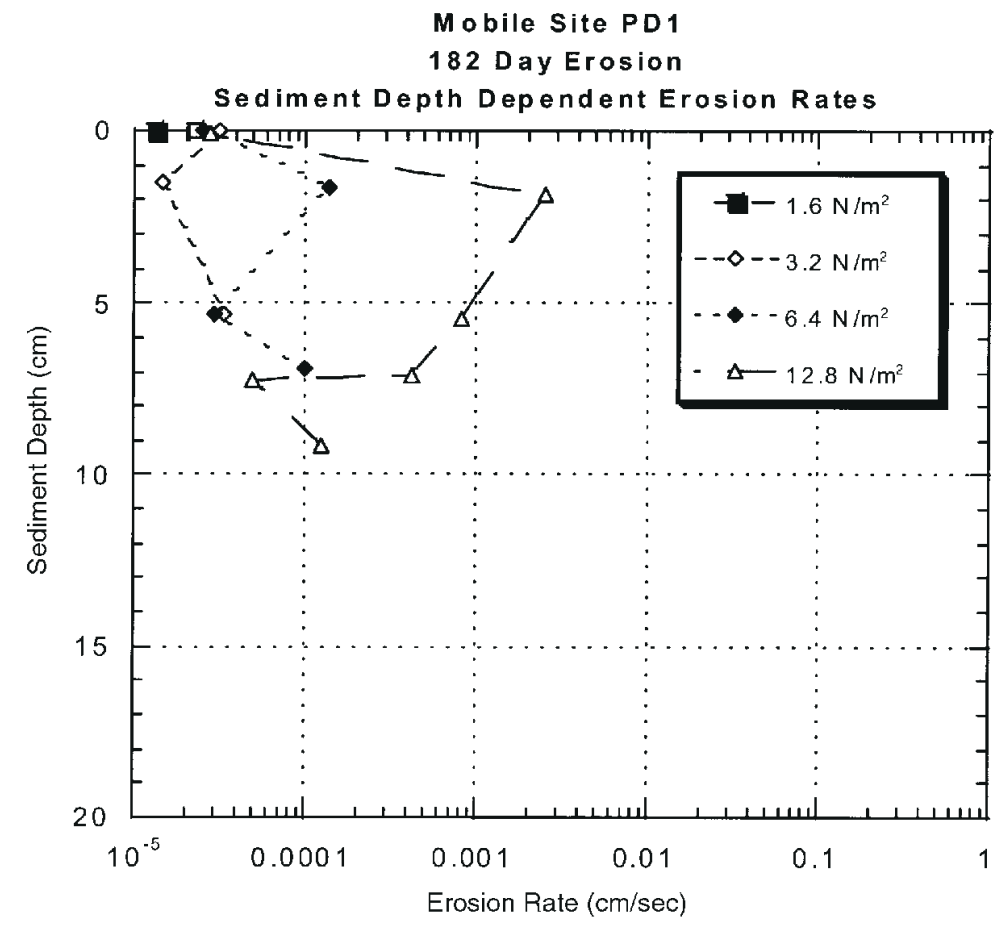

d. 182 days

Figure 6. (Concluded) 


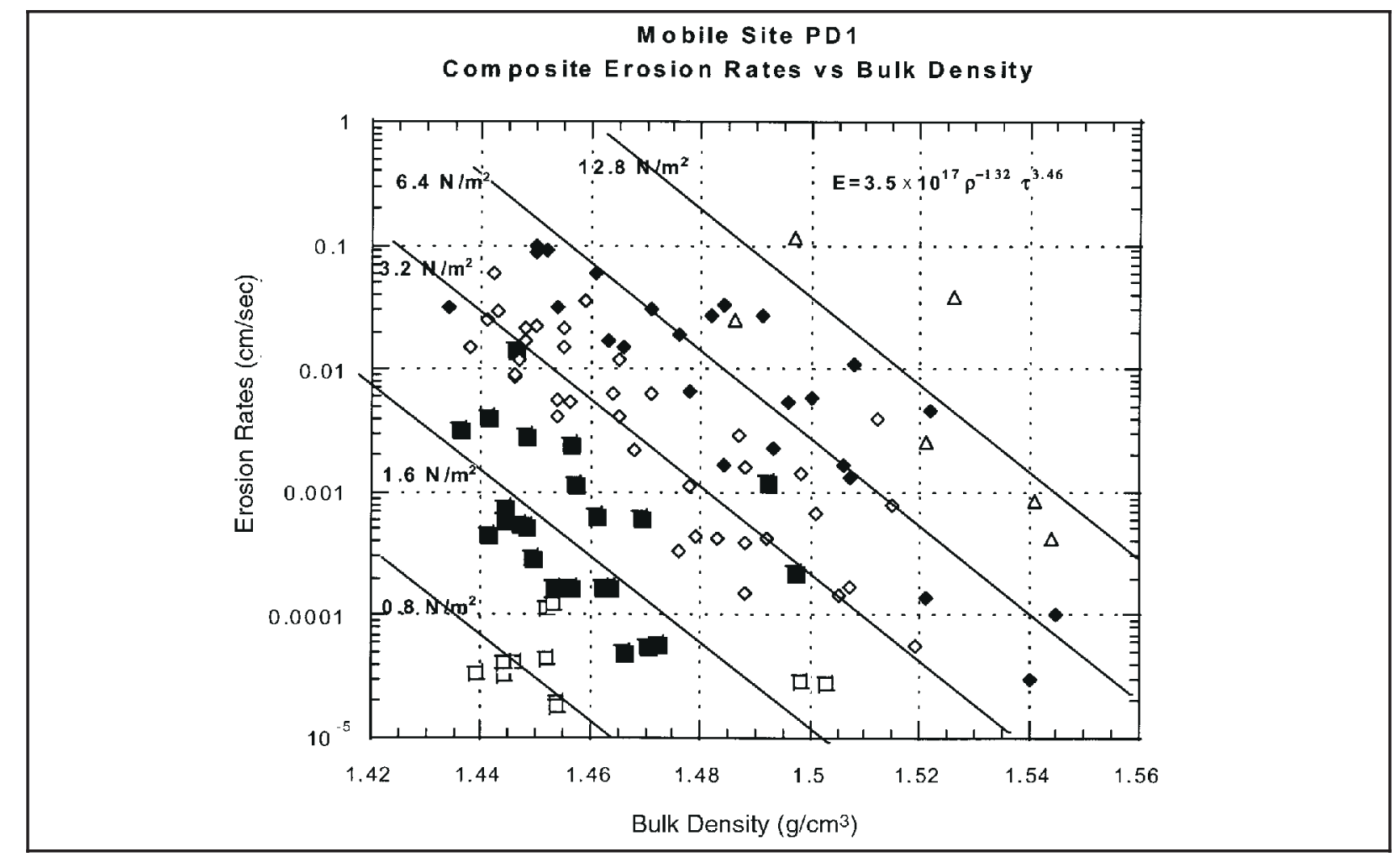

Figure 7. Erosion rates as a function of density with shear stress $\left(\mathrm{N} / \mathrm{m}^{2}\right)$ as a parameter. Straight lines are approximations by means of Equation 1

Effects of bentonite on erosion rates have been previously examined by Jin, McNeil, and Lick (2000) and are summarized in Gailani et al. (2001). However, the effects of other clay minerals have not been quantitatively determined but need to be in order to more quantitatively understand the effects of clay minerals. No systematic and/or quantitative investigations of the effects of manganese and iron oxidation and precipitation on erosion rates have been made; however, because of the large increase in the critical shear stress caused by this process, this needs further investigation.

The implications of the affects of smectite on erosion rates are significant when developing predictive models for site dispersion. If relationships are quantitatively known, then simple mineralogy tests of sediment scheduled for dredging could indicate if that material is minimally erosive. Ongoing research (Gailani et al. 2001) has indicated that the presence of bentonite (a member of the smectite family) will significantly reduce erosion rates. If further research indicates, as this Mobile sediment study implies, that most smectites are erosion resistant, then important conclusions can be extracted concerning dredged material behavior. Thus, for example, such a dredged material would be good for capping of contaminated material or for placement at an ODMDS where minimal dispersion is desired. In addition, a predominately sandy material with some smectite interspersed would be a poor choice for nearshore placement where beach nourishment is the goal. Further research is planned to define sediment erosion rates based on mineralogy and other bulk properties. This will assist districts in predicting erosion rates for dredged material. 
ACKNOWLEDGMENTS: This research was performed under a contract provided by the DOER program to the University of California at Santa Barbara. Dr. Wilbert Lick was the principal investigator. Research staff included Mr. Andy Kiehl, Dr. Joe McNeil, and Dr. Lijun Jin.

POINTS OF CONTACT: For more information, contact the principal investigator, Dr. Joseph Gailani (601-634-4851, Joe.Z.Gailani@erdc.usace.army.mil), the focus area chairman, Mr. Jim Clausner (601-634-2009, James.E.Clausner@erdc.usace.army.mil), or the Program Manager of the Dredging Operations and Environmental Research Program, Dr. Robert M. Engler (601-634-3624, Robert.M.Engler@erdc.usace.army.mil). This TN should be cited as follows:

Gailani, J. Z., Kiehl, A., McNeil, J., Jin, L. and Lick, W. (2001). "Erosion rates and bulk properties of dredged sediments from Mobile, Alabama," DOER Technical Notes Collection (ERDC TN-DOER-N10), U.S. Army Engineer Research and Development Center, Vicksburg, MS. www.wes.army.mil/el/dots/doer

\section{REFERENCES}

Adams, D. D., Fendinger, N. J., and Glotfelty, D. E. (1990). "Biogenic gas production and mobilization of in-place sediment contaminants by gas ebullition." Sediments: Chemistry and toxicity of in-place pollutants. R. Baudo, J. P. Giesy, and H. Muntau, ed., Lewis Publishers, Ann Arbor, MI.

Ariathurai, R., and Krone, R. B. (1976). "Finite element model for cohesive sediment transport," J. Hydr. Div., ASCE 102(3), 323-338.

Davis, J. E., Stauble, D. K., and Rollings, M. P. (2000). "Construction and monitoring of a mixed-sediment mound offshore of Mobile Bay, Alabama," DOER Technical Notes Collection (ERDC TN-DOER-N6), U.S. Army Engineer Research and Development Center, Vicksburg, MS. www.wes.army.mil/el/dots/doer

Fukuda, M. K., and Lick, W. (1980). “The entrainment of cohesive sediments in freshwater," J. of Geophysical Research 85(C5), 2813-2824.

Gailani, J. Z., Jin, L., McNeil, J., and Lick, W. (2001). "Effects of bentonite on sediment erosion rates," DOER Technical Notes Collection (ERDC TN-DOER-N9), U.S. Army Engineer Research and Development Center, Vicksburg, MS. www.wes.army.mil/el/dots/doer

Gotthard, D. (1998). “Three-dimensional, non-destructive measurements of sediment bulk density using gamma attenuation." Report, Department of Mechanical and Environmental Engineering, University of California, Santa Barbara, CA.

Jepsen, R., McNeil, J., and Lick, W. (2000). "Effects of gas generation on the density and erosion of sediments from the Grand River," J. Great Lakes Research 26, 209-219.

Jepsen, R., J. Roberts, and Lick, W. (1997). "Effects of bulk density on sediment erosion rates," Water, Air, and Soil Pollution 99, 21-31.

Jin, L., McNeil, J., and Lick, W. (2000). “Effects of Bentonite on Sediment Erosion Rates,” Report, Department of Mechanical and Environmental Engineering, University of California, Santa Barbara, CA.

Krone, R. B. (1962). "Flume studies of the transport of sediment in estuarial shoaling processes," Final Report to the U.S. Army Engineer District, San Francisco.

Lavelle, J. W., Mofjeld, H. O., and Baker, E. T. (1984). "An in situ erosion rate for fine-grained marine sediment," Journal of Geophysical Resarch 89(C4), 6543-6552.

McNeil, J., Jin, L., and Lick, W. (2000). "Effects of gas generation on the erosion of a capping material," Report, Department of Mechanical and Environmental Engineering, University of California, Santa Barbara, CA. 
McNeil, J., Taylor, C., and Lick, W. (1996). "Measurements of erosion of undisturbed bottom sediments with depth," J. Hydr. Engrg., ASCE 122(6), 316-324.

Partheniades, E. (1965). "Erosion and deposition of cohesive soils," J. Hydr. Div. ASCE 91, 105-139.

Roberts, J., Jepsen, R., Gotthard, D., and Lick, W. (1998). "Effects of particle size and bulk density on erosion of quartz particles," J. Hydr. Engr. 124(12), 1261-1267.

Taylor, C., and Lick, W. (1996). "Erosion properties of great lakes sediments," Report, Department of Mechanical and Environmental Engineering, University of California, Santa Barbara, CA.

NOTE: The contents of this technical note are not to be used for advertising, publication, or promotional purposes. Citation of trade names does not constitute an official endorsement or approval of the use of such products. 